\title{
Editorial
}

\section{Sociedad Iberolatinoamericana sobre Úlceras y Heridas (SILAUHE)}

Muy a menudo, muchas de esas ilusiones que un día cultivamos en nuestra mente no tienen oportunidad de verse materializadas, quizás por su envergadura, por necesitar la intervención de muchos y diferentes actores, porque a menudo esos sueños precisan de un altruismo y una filantropía cuya cotización, quizás, está en horas bajas en nuestra

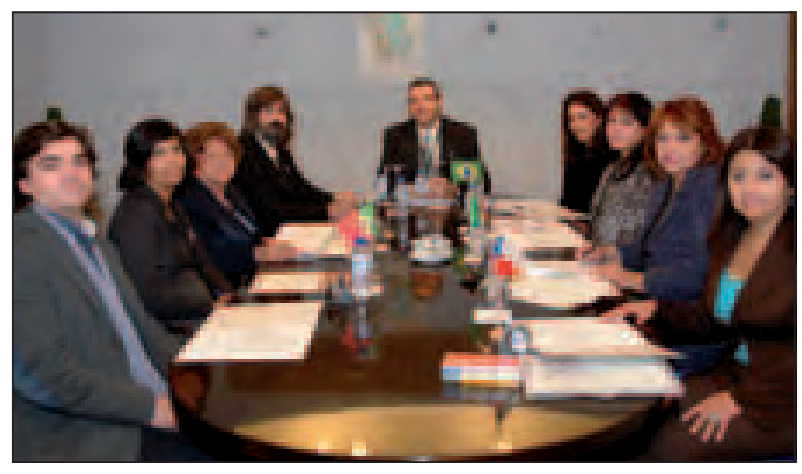
sociedad y, a veces, por la dificultad de acercar distancias en kilómetros o -aún más inquisitivas- en formación, credo o ideología.

Hoy celebro y comparto con todos los lectores de Gerokomos que un sueño, una ilusión, ha tomado forma hace unas pocas semanas, trenzado por el deseo, la sencillez, la dulzura y la voluntad de todos los que han dado forma inicial a este proyecto, echando por tierra a todos y a cada uno de esos obstáculos que, por la experiencia, se me antojaban posibles.

La Sociedad Iberolatinoamericana sobre Úlceras y Heridas tuvo su alumbramiento en un acto íntimo durante el pasado VII Simposio Nacional sobre Úlceras por Presión y Heridas Crónicas, celebrado en la ciudad de Tarragona, donde un grupo decidido de personas de elevada representatividad en el entorno de la atención de las heridas crónicas de diferentes países que engloban esa área geográfica (Gladis Rosa Camargo de Guaraz, presidenta del Grupo de Estudio de Heridas y Úlceras por Presión de Argentina; Mara Blanck y Celeste Dalia, presidenta y vicepresidenta de la Sociedade Brasileira de Enfermagem en Feridas e Estética; Isabel Aburto Torres, directora del Instituto Nacional de Heridas de Chile; Juana Jiménez Sánchez, directora de Enfermería y coordinadora de la Comisión Permanente de Enfermería de México; Katia Furtado, vicepresidenta del Grupo Asociativo de Investigaçao em Feridas de Portugal; Paulo J. Pereira Alves, de la Associaçao Portuguesa de Tratamento de Feridas, y Manuel Rodríguez Palma y Javier Soldevilla Agreda por parte del GNEAUPP) rubricó el compromiso de dar luz a una organización que brinde un espacio de encuentro y representatividad a profesionales de distintas disciplinas, asociaciones e instituciones oficiales de las diferentes naciones, que tengan como motor el trabajo para mejorar la atención de los pacientes con heridas crónicas.

Los fines demarcan claramente la intencionalidad de este nacimiento (agrupar, potenciar, fomentar, impulsar, consolidar, atender las necesidades de los profesionales que trabajen en el campo de la atención de las heridas, orientar, asesorar y cooperar con orga- 
